\title{
INVESTIGAÇÃO DIAGNÓSTICA NO ENSINO MÉDIO NA CIDADE DE MARINGÁ: UM ESTUDO DE CASO
}

\section{Juliana Pizani}

Universidade Estadual de Maringá, Maringá, Paraná, Brasil

Amauri Aparecido Bássoli de Oliveira

Universidade Estadual de Maringá, Maringá, Paraná, Brasil

Ieda Parra Barbosa-Rinaldi

Universidade Estadual de Maringá, Maringá, Paraná, Brasil

\begin{abstract}
Resumo
A pesquisa objetivou investigar, por meio de estudo de caso, o trato dos conhecimentos na Educação Física escolar, por parte de um professor do ensino médio, buscando compreender se a realidade das aulas tem atendido às premissas da área. Como técnica de coleta, utilizamos a observação das aulas e entrevista realizada. Os resultados indicam que a Educação Física ainda não se apresenta legítima no contexto escolar, mesmo que na lei tenha conseguido o status de componente curricular, uma vez que os conhecimentos abordados nas aulas não refletem satisfatoriamente as necessidades de mudanças paradigmáticas da área. Conclui-se que ainda há muito por ser feito e aplicado na área escolar em relação à Educação Física, sendo o professor o maior responsável por essa ação.
\end{abstract}

Palavras-chave: Educação Física. Educação. Conhecimento. Currículo.

\section{Introdução}

\begin{abstract}
Educação Física escolar, estando apoiada na Lei de Diretrizes e - Bases da Educação Nacional n. 9394/96 (BRASIL, 1996), passou a ser valorizada como um dos componentes curriculares da educação básica, devendo integrar o currículo em todos seus níveis de abrangência.

Entretanto, a simples inclusão da Educação Física como componente curricular não garante que ela tenha desenvolvimento didático satisfatório, visto que muitas são as questões que permeiam sua inclusão e, que, portanto, ela continua sendo entendida somente como atividade. Sobre o assunto, Castellani Filho (1988, p. 108) afirma que o termo atividade "ganha a conotação de um fazer prático não significativo de uma reflexão teórica", o que, na maioria dos casos, fica pre-
\end{abstract}


so no fazer pelo fazer, caracterizando a Educação Física como um campo de conhecimento desprovido de um saber.

O que se pode inferir é que a Educação Física foi incluída como componente curricular sem o devido planejamento que fundamentasse sua estruturação, resultando em uma falta de organização interna, tanto física quanto pedagógica, por parte dos profissionais da área. Dessa forma, a Educação Física escolar ainda não se apresenta legítima, posto que os profissionais envolvidos não trabalham de forma que contemple as necessidades educacionais contemporâneas no que se refere aos conhecimentos específicos da área, sendo facultativos em muitas das atuações docentes. Talvez isso possa ser justificado pelo fato de os professores terem dificuldade em sistematizar os conteúdos da área (PALMA et al., 2010).

O trato com o conhecimento nas aulas, por vezes, está relacionado à experiência que o professor possa ter tido ao longo de sua trajetória de vida (BARBOSA-RINALDI; SOUZA, 2003). Nessa direção, Silva et al. (2007) corroboram a delimitação dos conteúdos a serem abordados em relação ao domínio do conhecimento por parte do professor advém de sua formação acadêmica e pessoal, assim como de sua experiência escolar.

Tardif e Lessard (2007, p. 43) discutem sobre o trabalho docente, apontando que o ensinar é uma ação composta e que pode ser analisado como todo trabalho humano socializado em três dimensões: como atividade, como status e como experiência. Assim, o que se percebe é que a prática docente não pode estacionar-se apenas na experiência, pois é inegável que "ensinar, de certa maneira, é sempre fazer algo diferente daquilo que estava previsto pelos regulamentos, pelo programa, pelo planejamento, pela lição, etc.".

Assim, percebe-se que a Educação Física ainda não se estruturou e se legitimou, pois não possui uma organização sistematizada de seus conteúdos ou, ainda, nem mesmo se sabe de maneira concreta o que e como ensinar.

Oliveira (1999) aponta que, mediante a perspectiva de que a Educação Física abrange todos os níveis educacionais, surgem questões referentes aos conteúdos que deverão ser trabalhados nos diversos níveis da educação e de que forma serão tratados, bem como suas finalidades. Segundo o autor, outra problemática está relacionada ao desinteresse discente pelo universo do movimento estruturado e sistematizado em virtude da falta de organização curricular da Educação 
Física com sequência lógica de conhecimentos, tornando-a desconexa em relação ao cotidiano dos alunos, visto que não atendem às suas reais necessidades.

Podemos citar outros problemas que envolvem os condicionantes da Educação Física no contexto escolar, como a falta de recursos físicos e materiais e a rejeição da área pelas instâncias administrativas das escolas.

Desse modo, o interesse pelo trato dos conhecimentos específicos da Educação Física surgiu mediante a preocupação em relação ao sentido/significado e à importância dessa disciplina no contexto escolar, visando trazer contribuições para esse contexto.

Assim, a partir da necessidade de diagnosticar a situação da Educação Física escolar e as problemáticas existentes, estabelecemos as seguintes questões norteadoras: Como os saberes da Educação Física são tratados no contexto da Educação Física escolar? Será que esses conhecimentos se fazem presentes no planejamento do professor? Desse modo, como objetivo da pesquisa, propusemos investigar por meio de estudo de caso, o trato dos conhecimentos na Educação Física escolar, por parte de um professor do ensino médio, buscando compreender se a realidade das aulas tem atendido às premissas da área.

Com esta pesquisa, esperamos contribuir para a ampliação das possibilidades de entendimento e intervenção no universo escolar, visando à construção de uma realidade favorável para a presença da Educação Física como componente curricular.

\section{A opção metodológica e a realidade escolar}

Para melhor compreender a Educação Física escolar, acreditamos que seria necessário estar em contato direto com ela, desse modo, optamos por fazer um acompanhamento da rotina de um professor da área, desde o planejamento até a aplicação das aulas.

Por isso, realizamos um estudo de caso do tipo descritivo, tendo como propósito descrever de forma global o problema estudado com base em um caso específico e limitado (GIL, 2007). Utilizamos esse método para investigar um fenômeno particular com a oportunidade de generalizar os dados para outros contextos parecidos.

Assim, num primeiro momento entramos em contato com a coordenação pedagógica do colégio para pedir autorização para a realização do estudo, que nos encaminhou para o professor disponível em 
nos atender. $\mathrm{O}$ professor pesquisado concluiu sua graduação em Educação Física no ano de 2002, o mestrado em 2004 e atuou como professor substituto no ensino superior em uma universidade pública. Atualmente, é professor da rede estadual da educação básica com contrato pelo Processo Seletivo Simplificado (PSS). Vale salientar que o estudo foi aprovado pelo Comitê de Pesquisa e Ética com Seres Humanos (Copec), da Universidade Estadual de Maringá, n. 0296.0.093.000-07.

O estudo em campo foi realizado até a saturação das informações, culminando na observação de oito aulas, em três turmas do ensino médio, antecedidas por diálogos com o professor sobre o planejamento delas. Para complementar as observações, recorremos à entrevista semiestruturada como técnica de coleta, a qual objetivou elucidar informações pertinentes ao objeto estudado com questões que auxiliaram na compreensão de como os conhecimentos na Educação Física escolar vêm sendo tratados. Isso nos conduziu ao momento de mapeamento e interpretação dos dados coletados, que foi norteado pelo referencial da área.

Para melhor compreendermos a realidade encontrada na pesquisa, além da apresentação das questões feitas na entrevista, trouxemos as informações registradas em diário de campo durante as observações das aulas. Isso porque a prática docente observada acaba por reforçar e caracterizar a Educação Física como uma simples atividade não obrigatória, na qual os alunos fazem o que têm vontade de fazer.

Em relação aos conteúdos perguntamos ao professor: Qual estratégia você utiliza para selecionar os conhecimentos da disciplina?

Depende da escola. Trabalho numa escola que é o reduto do futsal, então lá eu só trabalho futsal. A "mulecada" não quer ficar dentro de sala de aula. Na $5^{\mathrm{a}}, 6^{\mathrm{a}}$ e $7^{\mathrm{a}}$ séries eu procuro trabalhar mais as regras do vôlei e do futsal, mais voltado como esporte. Já no ensino médio são aquelas questões do livro da secretaria de educação. O que é saúde, se eles fazem atividade física três vezes por semana, tentando conscientizar os alunos. Mas só utilizo o livro quando chove ou quando tem uma situação que não posso ir para quadra.

Percebemos que não há critérios para selecionar os conteúdos a serem trabalhados, o que distancia a prática pedagógica da proposta 
preconizada nas Diretrizes Curriculares do Estado do Paraná, a qual tem sua fundamentação baseada em Soares et al. (1992, p.31), que defendem que "os princípios de seleção do conteúdo remetem à necessidade de organizá-lo e sistematizá-lo fundamentado em alguns princípios metodológicos, vinculados à forma de como serão tratados no currículo, bem como à lógica com que serão apresentados aos alunos".

Foi possível observar que, mesmo sendo escolhidas duas manifestações esportivas para serem trabalhadas (vôlei e futsal), elas não foram desenvolvidas de forma satisfatória, pois o seu tratamento não passou do simples "rola bola" criticado por autores como Darido e Sanches Neto (2005) e Souza Júnior (2001).

Nas aulas observadas, a sistematização do conteúdo, os objetivos da aula, diálogos entre professor-aluno, questionamentos, entre outros aspectos tidos como importantes para a compreensão e assimilação do que está sendo ensinado não se fizeram presentes, tornando-se questionável, segundo Darido e Sanches Neto (2005), se os alunos aprendem sem a intervenção ativa do professor. Outro ponto de destaque é que as aulas não apresentaram uma organização lógica. O início e o fim não se diferenciavam, a não ser pelo placar do jogo.

No entanto, mesmo a aula acontecendo da forma como os alunos queriam que acontecesse, a participação não era unânime. Muitos alunos se negavam a participar e, durante toda a aula, permaneciam sentados numa conversa que se tornava mais atraente do que o que estava sendo tratado em aula. Ao questionar o professor: Qual o papel da Educação Física escolar?

A função da Educação Física é colocar a "mulecada" pra jogar. Ter uma prática, vivência, fazer exercício. A Educação Física deveria ser só prática. É para desestressar, sair da sala de aula.

Como ponto de partida, de acordo com Palma et al. (2010, p. 31), a Educação Física como disciplina obrigatória do currículo escolar deve primar pela unicidade da teoria e prática e,

não pode ter tarefas diferentes dos demais componentes do contexto, muito embora apresente particularidades (saberes) que são próprias da área. Portanto, ela deve ser considerada como uma matéria escolar que objetiva o ensino de conhecimen- 
tos, sendo o movimento culturalmente construído seu referencial primário.

Segundo Damasceno (1987, p. 45), dar primazia à prática em detrimento da teoria, e vice-versa, do ponto de vista pedagógico, acaba sendo uma prática desprovida dos ingredientes teóricos e uma teoria descomprometida com as mudanças e transformações que só podem se efetivar por meio da prática. Nesse sentido, Souza (2001, p. 7) afirma que, "teoria e prática constituem um todo único, produzido na dinâmica da evolução humana em um contexto e em um tempo. Não há prevalência de uma sobre a outra, há interdependência". Isso porque, de acordo com a mesma autora, é "na prática que a teoria tem seu nascedouro, sua fonte de desenvolvimento e sua forma de consecução, é na teoria que a prática busca seus fundamentos de existência e transfiguração" (SOUZA, 2001, p. 8).

Assim, é possível inferir que a defesa dos autores se contrapõe ao entendimento de Educação Física do professor entrevistado, que não compreende que o trabalho pode privilegiar a relação da teoria e da prática.

Outra confirmação obtida que reflete essa separação teoria e prática é a forma de pensar os processos avaliativos. Recebemos a seguinte resposta ao perguntamos qual a forma de acompanhamento dos alunos, você faz uso de processos avaliativos?

Minha avaliação é superficial, ainda mais quando pego substituição. Eu acredito que na Educação Física a nota tem que ser 6,0 da prática e 4,0 de trabalhos.

Mesmo havendo uma valorização da prática em detrimento da teoria no contexto da Educação Física escolar, a avaliação ainda acontece de forma superficial, pois ficou claro que esta não é importante na visão docente, posto que a prática de alguma atividade no horário da aula é o que sempre se sobressai.

O que se observa é uma repetição de conteúdos, sempre valorizando a performance esportiva, a competição e o distanciamento dos conteúdos em relação ao cotidiano dos alunos. Nesse sentido, o que ocorre é uma falta de intenção formativa e informativa por parte dos conteúdos, bem como estratégias metodológicas, ocasionando uma 
prática educativa sem sentido no âmbito do processo de ensino (OLIVEIRA, 1999).

$\mathrm{O}$ ato de avaliar fornece dados que permitem verificar diretamente o nível de aprendizagem dos alunos e, indiretamente, determinar a qualidade do processo de ensino. A avaliação funciona como um feedback para que o professor repense sua prática docente, isso porque a prova nada mais é que um reflexo da aula, pois os alunos reproduzem nestas aquilo que o professor trabalha em sala de aula. Por isso, a prova, segundo Moretto (2003), não deve ser vista como um acerto de contas com os alunos, e nem a nota como uma resposta positiva de total aprendizagem para os pais e professores, mas, sim, como um momento privilegiado de estudo. De tal modo, ao entender a função primordial da avaliação para o contexto educacional, também compreenderemos que o ato de ensinar não é uma simples transmissão de conhecimentos prontos e acabados, conjunto de verdades que os alunos devem receber e gravar para então reproduzir na hora da prova. $\mathrm{O}$ ato de ensinar necessita apresentar novos valores, novos significados, para que os alunos aprendam com prazer, podendo fazer relações com o contexto em que vivem (MORETTO, 2003).

Ao contrário, se não percebermos a educação por esse aspecto, ela passa a não ter sentido dentro do processo de ensino, uma vez que ainda não possui uma forma clara da seleção e seriação dos conteúdos de maneira sistemática e que contribua para o processo de formação, aquisição e produção de conhecimento por parte dos alunos.

Em relação à organização e planejamento, realizamos as seguintes questões: Como se dá sua participação no processo de elaboração do projeto político pedagógico (PPP)? "Por eu ser PSS nem sempre estou na escola no início do ano letivo". Como você considera o PPP na estruturação e desenvolvimento de sua aula? "O PPP é bonito, engloba tudo, capoeira, ginástica... Só que nem sempre tem uma estrutura adequada pra isso".

Observa-se que em ambas as respostas não há uma participação efetiva, tendo ainda como agravante a discordância do previsto no PPP. Sobre o assunto, Oliveira et al. (2011) destaca que o PPP, mesmo sendo entendido como alicerce pedagógico, porque torna-se instrumento de autonomia por meio de construção coletiva, muitos docentes ainda não participam de sua elaboração e/ou não o tomam como referência de sua ação diária. 
Quando pensamos no projeto pedagógico, este nos dá a ideia de um planejamento que abrange todo o contexto escolar e que, portanto, deveria ter a participação de todos os envolvidos com a escola. No entendimento de Libâneo et al. (2007, p. 357), este "deveria ser pensado, discutido e formulado coletivamente, também como forma de construção da autonomia da escola, por meio da qual toda a equipe é envolvida nos processos de tomada de decisões sobre aspectos da organização escolar e pedagógico-curriculares".

Sabemos que a efetivação da elaboração coletiva do PPP ainda é precária, e a resposta do professor pesquisado confirma essa problemática. Percebe-se que não há concordância com o previsto no projeto, reafirmando o que acontece em boa parte das escolas, em que os professores não demonstram preocupação com o todo, apenas com suas atividades de aula, que, por vezes, não atendem aos objetivos escolares previstos no projeto político pedagógico.

Segundo Veiga (2003, p. 275), deve haver "engajamento coletivo para integrar ações dispersas, criar sinergias no sentido de buscar soluções alternativas para diferentes momentos do trabalho pedagógicoadministrativo, desenvolver o sentimento de pertença". Os professores, quando não participam de sua elaboração e não o reconhecem como importante para o contexto, também não assumem a escola como algo integralizado no processo educativo e não se preocupam com um trabalho pedagógico para além de ato isolado, como um trabalho que possui especificidades metodológicas.

Mediante essas respostas sobre o PPP, também perguntamos: Quais são as dificuldades e facilidades encontradas para o desenvolvimento da Educação Física escolar? Já buscou cursos de formação para suprir as necessidades encontradas?

Falta consciência dos alunos em saber da importância da prática da atividade física. Já tentei trabalhar teórica com eles e passei raiva. Eu não tenho facilidade para trabalhar com dança, lutas, ginástica... Então eu não trabalho, mas nunca procurei me aperfeiçoar, porque os cursos ficam muito distantes da nossa realidade.

O que se observa na fala do professor é que, novamente, sua prática docente se caracteriza desprovida de teoria, tendo forte relação 
com o entendimento de que a atividade física é uma prática necessária à vida dos alunos.

Um ponto negativo é a realização de aulas teóricas no padrão comumente estabelecido. Para minimizar esse conflito de aceitação dos alunos, sugere-se buscar estratégias para trabalhar os conhecimentos de forma que a teoria esteja em constante associação com a prática. No entanto, isso não descarta a necessidade de algumas aulas serem realizadas em sala e não na quadra poliesportiva ou outro espaço típico da Educação Física escolar. O professor também reconhece que não tem facilidade para trabalhar com conhecimentos para além dos esportes. Contudo, nem todos os esportes são desenvolvidos em sua ação docente, visto que assume que apenas o futsal e o vôlei fazem parte de suas aulas, e estes não apresentam planejamento e organização, caracterizando-se apenas como jogo com fim em si mesmo.

Quando refletimos sobre estarmos inseridos numa sociedade do conhecimento, a busca por atualizações e diversas formas de aprendizagem é uma constante necessidade. Não faz sentido acreditar que a formação inicial ofertará subsídios suficientes para a ação docente no contexto escolar, por vezes ela é apenas o início. Segundo Rodrigues (1988), o professor deve ser comprometido politicamente e tem que ser tecnicamente competente. Para isso, ele necessita preparar sua técnica, ampliar e atualizar seus conhecimentos e, então, o exercício frequente e diário por parte do educador sobre o sistema em que está inserido é indispensável.

A formação continuada é uma possibilidade para propor novas metodologias e promover aos profissionais o acesso às discussões atuais da área, visando contribuir para a melhoria da ação pedagógica na escola e, consequentemente, na educação (NÓVOA, 1992).

No entanto, é importante destacar que os professores estão envoltos em dificuldades como: carga horária de trabalho elevada; baixos salários, que, por vezes, desestimulam a atuação docente; falta de incentivo governamental; falta de organização nas escolas; contratos de substitutos em grande continuidade, entre outros problemas.

Em relação à formação, fizemos o seguinte questionamento: $D e$ que modo você analisa os conhecimentos vivenciados na formação e as exigências no campo efetivo de desenvolvimento da profissão - escola? 
Na universidade eu vivia na ilusão de que o contexto escolar era lindo. Só que na realidade é outra coisa. Nem sempre o que está no papel é cumprido. Essas pessoas que querem mudar precisam se aproximar da realidade. Os professores universitários fazem planejamento da capoeira, da dança e da ginástica na escola, ficam muito distante do contexto escolar. A nossa grande tristeza é não trabalhar a realidade da escola.

O professor evidencia um descontentamento com a formação inicial, demonstrando certo distanciamento com a realidade escolar. No tocante a isso, Nóvoa (1992) destaca que a formação de professores, por vezes, não compreende que a lógica da atividade educativa nem sempre acontece como preveem as dinâmicas próprias da formação, não valorizando a articulação necessária e indispensável entre o processo de formação de professores e os projetos escolares. No entanto, nesse caso, o referido professor já teve a oportunidade de formação continuada em um curso de mestrado, e mesmo assim continua culpando a formação inicial pela sua falta de articulação com a realidade escolar.

Sobre a valorização do teor prático da Educação Física, de acordo com o professor pesquisado, para que os alunos tenham acesso à prática de atividade física, perguntamos: $O$ modo como a Educação Física escolar vem sendo trabalhada supre a necessidade de atividade física que os alunos não fazem fora do contexto das aulas? E a resposta obtida foi:

Se todos os alunos fizessem a aula, supriria a necessidade da prática de atividade física. Se tiver futsal quatro vezes por semana tem aluno que vai jogar quatro vezes.

Historicamente, a atividade física tem sido relacionada à promoção e manutenção da saúde. De acordo com Bagrichevsky e Palma (2004), os aspectos fisiológicos parecem ainda ser mais explorados nos estudos sobre saúde nesse contexto, se comparados a outros enfoques. Assim, com base em Devide (2002), o professor deve relacionar os conhecimentos tratados na Educação Física com a realidade de seus alunos e estar ciente da concepção equivocada no que tange à Educação Física como promotora de saúde. Todavia, faz-se necessária a apropriação do conceito multifatorial de saúde e sua dimensão social, 
pois o educador, provido de instrumentação teórica consistente, poderá tecer discussões que superem o paradigma hegemônico da aptidão física, tornando-se uma via de educação para a saúde dos alunos, para que esses tenham uma postura crítica que contribua para a desmistificação da visão deturpada existente entre o exercício físico e a saúde.

Em relação à escolha do vôlei e futsal como conteúdos da Educação Física escolar, percebemos que o esporte que se faz presente na atuação desse professor ainda é um conhecimento precário. Mesmo tendo as Diretrizes Curriculares do Estado do Paraná (DCEs) como eixo norteador para o trabalho com a disciplina de Educação Física escolar, a qual tem os esportes como conteúdo estruturante, além da formação inicial que trabalha impreterivelmente com os conhecimentos pertinentes a essas manifestações, o professor não traz em sua prática docente, bem como na entrevista, conhecimento e aprofundamento científico de suas especificidades, pois no momento em que este não apresenta para os alunos os saberes específicos da manifestação a ser trabalhada, entende-se que não compreende o universo que a constitui.

Dessa forma, as aulas do professor pesquisado não atendem às premissas da área, uma vez que não tratam dos conhecimentos clássicos pertinentes a elas, como jogos e brincadeiras, esporte, dança, lutas e ginástica, e quando são desenvolvidos não recebem o tratamento condizente com os objetivos educacionais. Isso porque o professor não busca romper com a maneira tradicional do trato com os conhecimentos da Educação Física, por meio de discussões acerca de elementos articuladores, que têm como componentes centrais o corpo, a ludicidade, a saúde, o mundo do trabalho, a desportivização, a técnica e a tática, o lazer, a diversidade e a mídia (PARANÁ, 2008).

Embasados em Betti e Zuliani (2002), acreditamos que ainda fazse necessário introduzir e integrar o aluno aos conhecimentos da cultura corporal de movimento, oportunizando que o cidadão em formação possa utilizar os saberes da área para o benefício da qualidade de vida. Em especial no ensino médio, os autores destacam que a Educação Física precisa apresentar características próprias e inovadoras e que levem em consideração a fase cognitiva e afetivo-social vivida pelos adolescentes.

Nessa direção, as DCEs entendem que a escola se configura como um espaço que deve garantir ao aluno o acesso aos conhecimentos historicamente produzidos pela humanidade. Assim, como compo- 
nente curricular obrigatório do currículo escolar, tendo como objeto de estudo e ensino a cultura corporal, necessita proporcionar aos alunos a reflexão crítica das diversas manifestações corporais construídas pelos homens ao longo da história, buscando "contribuir com um ideal mais amplo de formação de um ser humano crítico e reflexivo, reconhecendo-se como sujeito, que é produto, mas também agente histórico, político, social e cultural" (PARANÁ, 2008, p. 49).

Ainda, vale salientar que as respostas obtidas na entrevista refletem na prática docente ações restritas ao ensino do esporte. Portanto, levando em consideração uma escola baseada numa pedagogia crítica, esta deve exigir coerência dos conteúdos selecionados com o objetivo de promover a leitura da realidade, sendo direito de todo cidadão o acesso a todos os conhecimentos da área, haja vista que, em conjunto com outras áreas, poderá contribuir para a (re)construção dos saberes historicamente produzidos pelo homem de forma mais efetiva e satisfatória, possibilitando que os alunos compreendam seu papel como partícipes na transformação da realidade.

\section{Considerações finais}

Por meio da pesquisa realizada, bem como do referencial teórico da área, entendemos que existe um rol de conhecimentos clássicos que os alunos têm direito de conhecer e vivenciar e que a Educação Física deveria assumir a responsabilidade de proporcionar aos alunos o acesso a tais conhecimentos.

Em nossa inserção em campo, por meio das informações obtidas nas observações e na entrevista realizada, evidenciamos que, mesmo a Educação Física tendo avançado em relação à lei, ainda não se apresenta legítima a ponto de ser valorizada no contexto escolar, para ser trabalhada de forma que contemple os conhecimentos preconizados pela área e que se fazem presentes nas DCEs.

Os resultados do estudo revelam que os conhecimentos abordados nas aulas observadas não refletem satisfatoriamente a necessidade de mudanças paradigmáticas da Educação Física. Indicam a dificuldade dos próprios professores da área em compreendê-la. Como ponto de intervenção, sinalizamos também a carência de uma sistematização dos conhecimentos da Educação Física, para que aconteçam avanços significativos na área. 
Contudo, ao apresentar este estudo, a sensação é a de que demos mais um passo para que avanços significativos aconteçam em relação ao trato dos saberes próprios da Educação Física escolar. Assim, este estudo inclui-se no "muito já feito", não apenas porque nos possibilitou o acesso à realidade das ações pedagógicas referentes à Educação Física escolar, consideradas por nós como fundamentais para o desenvolvimento de uma prática condizente com a área em questão, mas também pelo fato de que será mais uma fonte de possíveis reflexões sobre a prática pedagógica de professores.

\title{
Diagnostic research in high school in the city of Maringá: a case of study
}

\begin{abstract}
The research aimed to investigate, through of a case study, the deal of knowledge in physical education, by a high school teacher, seeking to understand the reality of the classroom has met the assumptions of the area. We use as a collection technique to observe classes and interview. The results indicate that physical education has still not legitimate in the school context, even though the law has achieved the status of curricular component, since the knowledge covered in class does not reflect satisfactorily the needs of change paradigmatic of the area. We conclude that there is still much to be done and applied as the school in relation to physical education, being the teacher most responsible for this action.
\end{abstract}

Keywords: Physical Education. Education. Knowledge. Curriculum.

Investigación diagnóstica en la escuela secundaria en la ciudad de Maringá: un estudio de caso

\section{Resumen}

La investigación tuvo como objetivo investigar, a través de un estudio de caso, por un profesor de secundaria, la oferta de conocimientos en educación física, tratando de comprender si la realidad de las aulas ha cumplido con los supuestos de la zona. Utilizamos la observación de clases y la entrevista como técnica de recolección. Los resultados indican que la educación física aún no ha legítima en el contexto escolar, a pesar de que la ley ha alcanzado el status de los componentes curriculares, posto que los conocimientos en clase no reflejan las necesidades de cambiar los paradigmas de la zona. Llegamos a la conclusión de que todavía hay mucho por hacer en la escuela en relación a la educación física, siendo el maestro lo más responsable por esta acción.

Palabras clave: La Educación Física. Educación. Conocimiento. Curriculum

\section{Referências}

BAGRICHEVCKY, M.; PALMA, A. Questionamentos e incertezas acerca do estatuto científico da saúde: um debate necessário na edu- 
cação física. Revista da Educação Física, Maringá, v.15, n.2, p.5766, 2. sem. 2004.

BARBOSA-RINALDI, I. P.; SOUZA, E. P. M. de. A Ginástica no percurso escolar dos ingressantes dos cursos de licenciatura em educação física da Universidade Estadual de Maringá e da Universidade Estadual de Campinas. Revista Brasileira de Ciências do Esporte, v. 24, n. 3, p.159-173, maio 2003.

BRASIL. Ministério da Educação e Cultura. Lei de diretrizes e bases da educação nacional n. 9.394, de 20 de dezembro de 1996. Diário Oficial da União, Brasília, DF, 20 dez. 1996.

BETTI, M.; ZULIANI, L. R. Educação Física escolar: uma proposta de diretrizes pedagógicas. Revista Mackenzie de Educação Física e Esporte, ano 1, n. 1, p. 73-81, 2002.

CASTELLANI FILHO, L. Educação física no Brasil: a história que não se conta. Campinas: Papirus, 1988.

DAMASCENO, M. N. A relação teoria-prática na ação docente. Revista Educação em Debate, ano 10, n. 13, p. 40-51, 1987.

DARIDO, S. C.; SANCHES NETO, L. O contexto da educação física na escola. In: DARIDO, S. C.; RANGEL, I. C. A. (Coord.). Educação física na escola: implicações para a prática pedagógica. Rio de Janeiro: Guanabara Koogan, 2005. p. 50-61. (Coleção Educação Física no Ensino Superior).

DEVIDE, F. P. Educação física, qualidade de vida e saúde: campos de intersecção e reflexões sobre a intervenção. Revista Movimento, Porto Alegre, v. 8, n. 2, p. 77-84, maio/ago., 2002.

GIL, A. C. Como elaborar projetos de pesquisa. 4. ed. São Paulo: Atlas, 2007.

LIBÂNEO el al. Educação escolar: políticas, estrutura e organização. 5. ed. São Paulo: Cortez, 2007.

MORETTO, V. P. Prova: um momento privilegiado de estudo não um acerto de contas. 3. ed. Rio de Janeiro: DP\&A, 2003. 
NÓVOA, A. Formação de professores e profissão docente. In: NÓVOA, A. (Coord.). Os professores e a sua formação. Lisboa: Dom Quixote, 1992, p. 15-34.

OLIVEIRA, A. A. B. de. Educação física no ensino médio - período noturno: um estudo participante. 1999. Tese (Doutorado em Educação Física), Faculdade de Educação Física da Universidade Estadual de Campinas, São Paulo, 1999.

. et al. Projeto político pedagógico: elaboração e aplicação nas escolas públicas de Maringá. Revista Movimento, Porto Alegre, v. 17, n. 1, p. 77-94, jan./mar., 2011.

PALMA, et al. Educação física e a organização curricular: educação infantil, ensino fundamental, ensino médio. 2. ed. Londrina: Eduel, 2010.

PARANÁ. Secretaria de Estado da Educação. Diretrizes Curriculares da Educação Básica. Educação Física. Curitiba: SEED, 2008.

RODRIGUES, N. Da manifestação da escola à escola necessária. São Paulo: Cotez, 1988. p. 66-67.

SILVA et al. Educação física escolar em Maringá: experiência de ensino-aprendizagem no cotidiano das aulas. Revista Brasileira de Ciências do Esporte, Campinas, v. 28, n. 2, p. 69-83, jan. 2007.

SOARES et al. Metodologia do ensino da educação física. São Paulo: Cortez, 1992.

SOUZA JÚNIOR, M. O saber e o fazer pedagógicos da educação física na cultura escolar: o que é um componente curricular. In: CAPARROZ, F. E. (Org.). Educação física escolar: política, educação e intervenção. Vitória: Proteoria, 2001.

SOUZA, N. A. de. A relação teoria-prática na formação do educador. Semina: Ci. Soc. Hum., Londrina,v. 22, p. 5-12, set. 2001.

TARDIF, M.; LESSARD, C. O trabalho docente: elementos para uma teoria da docência como profissão de interações humanas. 3. ed. Petrópolis: Vozes, 2007. 
VEIGA, I. P. A. Inovações e Projeto Político-Pedagógico: uma relação regulatória ou emancipatória? Cad. Cedes, Campinas, v. 23, n. 61, p. 267-281, dezembro 2003.

Recebido em: $12 / 08 / 2011$

Revisado em: 24/11/2011

Aprovado em: 02/02/2012

\section{Endereço para correspondência}

parrarinaldi@hotmail.com

Ieda Parra Barbosa-Rinaldi

Universidade Estadual de Maringá

Centro de Ciências Biológicas, Departamento de Educação Física.

Avenida Colombo, 5790, Câmpus Universitário

Jardim Universitário

87020-900 - Maringa, PR - Brasil 